\title{
Incubation of the galvanic skin response as a function of design and delay characteristics'
}

\author{
Honald E. Sehaub and John A. MeNulty \\ DALHOUSIE UNIVERSITY
}

\begin{abstract}
Abstraet
Incubation of the human GSR was studied using a "between-subjects" design. The phenomenon appeared when Ss were removed from the apparatus during the delay, but not when they were left in. In the latter case, the GSR to test stimuli appeared to increase as a function of time in the situation.
\end{abstract}

\section{Problem}

A number of studies have demonstrated that when a neutral stimulus is paired with a painful stimulus, and varying periods of time are allowed to lapse between this pairing and subsequent testing, the neutral stimulus tends to evoke larger and larger GSRs (Bindra \& Cameron, 1953; Diven, 1937; Golin, 1961; Mednick, 1957). All of the previous studies had one characteristic in common: all employed within-subject controls. The purpose of the present experiment was to attempt to demonstrate incubation using a between-subject design. A second variable, the activity of the S during the incubation period, was added as a further test of the generality of the phenomenon.

\section{Method}

Ninety male undergraduates from the introductory psychology class at Dalhousie University served as Ss.

Ss were comfortably seated in the experimental room and read instructions which contained three main points-that we were interested in obtaining some measures in response to certain stimuli, none of the stimuli would be harmful, and things might be a little boring. Ss were connected to a Sanborn polygraph equipped to measure GSR, heart rate, respiration, and muscle potential. Only GSR data will be reported. The GSR was recorded from the index and ring fingers of S's right hand using finger-tip electrodes. Continuous recordings were made except where noted below.

White noise at $64 \mathrm{db}$ (re .0002 dynes $/ \mathrm{cm}^{2}$ ) was delivered to a 3 in speaker located about $4 \mathrm{ft}$ above S's head via a Grason-Stadler white noise generator. Shock was presented to the finger tips of the left hand through electrodes identical to the GSR electrodes. A Grass SD5 Square Wave Stimulator was set at $40 \mathrm{v}$ (30 cps). Stimulus durations and intervals were controlled by a pair of Hunter electronic timers.

Ss were randomly assigned to 18 groups of five Ss each in what was essentially a $3 \times 3 \times 2$ factorial design. The three factors were: (1) type of initial training, (2) duration of delay (incubation) period, and (3) activity during the delay period.

1. Type of initial training: Three training procedures were employed. Experimental groups (EXP) were presented with six classical CS-US pairings starting approximately $2 \mathrm{~min}$. after $\mathrm{E}$ left the experimental area. Each trial consisted of $3.5 \mathrm{sec}$. white noise terminated by .5 sec. shock. The interval between noise onset and shock onset was $3 \mathrm{sec}$. Adaptation control groups (AC) received six presentations of the white noise alone during training. Time control groups (TC) were maintained in the situation for the same length of time as EXP and AC groups, but without any stimulus presentations.

2. Delay duration: The three training groups were each split into three equal sub-groups corresponding to three delay periods of 0,5 , or $30 \mathrm{~min}$. Following initial training, the appropriate delay period was introduced.

3. Activity during delay: Two activities were used in the delay period. One-half of the Ss in each of the training $x$ delay groups described above remained in the experimental situation without any further instructions for the duration of the delay. (These will be referred to as IN groups.) The other half was removed from the apparatus and told to wait in the corridor for the appropriate delay. (These will be referred to as OUT groups.) Zero min. -OUT groups actually remained in the situation and proceeded directly to the test phase. Although there were no procedural differences between $0 \mathrm{~min}$. -IN and $0 \mathrm{~min}$. -OU T groups, both were run to maintain design symmetry. At the end of the delay, OUT groups were brought back in and again hooked up to the apparatus.

Testing consisted of two $3.5 \mathrm{sec}$. white noise presentations at a $1 \mathrm{~min}$. interval and was identical for a 11 groups. OUT groups received the first test trial $1 \mathrm{~min}$. after returning to the experimental situation.

(The descriptive notations used in the remainder of the paper will refer to each of the three factors. For example $\mathrm{EXP}_{30-\mathrm{IN}}$ refers to the experimental group receiving both shock and noise during training followed by a $30 \mathrm{~min}$. delay during which they remained in the situation.)

\section{Results and Diseussion}

The GSR in conductance change was calculated for each $\mathrm{S}$ on each trial. However, only the data from the first test trial is presented here. The change measure was based on the level immediately preceding noise onset and the maximum deflection occurring up to $7.5 \mathrm{sec}$. after noise onset. Figure 1 shows the mean GSR for each group on the first test trial. A $3 \times 3 \times 2$ analysis of variance of these data showed three significant 


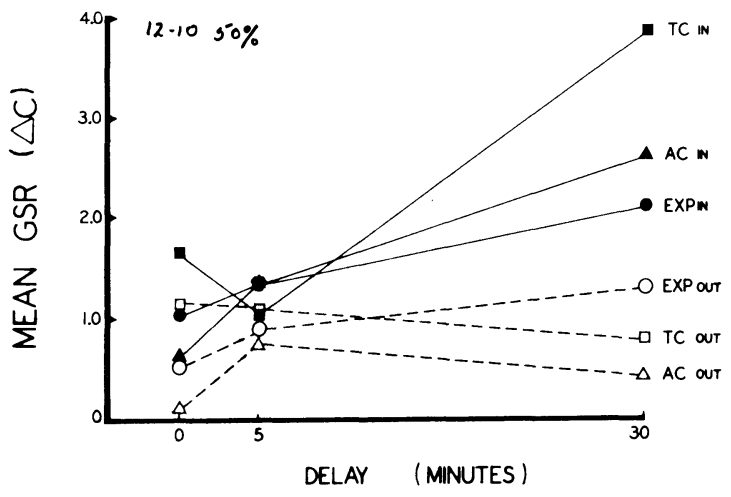

Fig. 1. Mean GSR on the first test trial as a function of delay duration. Each point represents an independent group. (See text.)

effects: Delay Duration $(\mathrm{F}=7.61 ; 2,72 \mathrm{df} ; \mathrm{p}<.005)$, IN-OUT $(\mathrm{F}=18.85 ; 1,72 \mathrm{df} ; \mathrm{p}<.005)$ and the Delay $x$ IN-OUT interaction $(F=5.88 ; 2,72 \mathrm{df} ; \mathrm{p}<.005)$. Thus Ss maintained in the situation showed significantly greater GSRs than Ss removed from the situation. Furthermore, the longer the delay the greater the response for the IN groups. There were no significant effects due to differences in initial training.

The most marked separation among the different groups was after a $30 \mathrm{~min}$. delay. Among the $30-\mathrm{IN}$ groups, the $\mathrm{EXP}_{30-\mathrm{IN}}$ group showed the smallest response; in the 30 -OUT groups the $\mathrm{EXP}_{30-O U T}$ group showed the largest response. This latter finding is the only evidence of incubation as defined in previous studies.

More interesting, perhaps, is the relationship among the three training groups in the 30-IN condition. Not only did we fail to find incubation in these groups, but both control groups showed a greater mean GSR than the EXP group. Clearly, some mechanism other than incubation is functioning to increase the GSR over time. This mechanism cannot be mere recovery from training adaptation for two reasons: (1) The response to test stimuli in the 30-IN groups was considerably greater than that observed on the first training trial. (2) The group showing the greatest mean GSR was the $\mathrm{TC}_{30-\mathrm{IN}}$ group which had had no previous experience with the test stimulus.

It is apparent from these results that some temporal factor is functioning to cause an increased GSR during "silent" periods in the experimental situation. The existence of such a mechanism raises interesting possibilities for studies of GSR adaptation and conditioning. For example, both Lovibond (1964) and Stewart, Stern, Winokur, \& Fredman (1961) have noted that intertrial intervals are generally less than $1 \mathrm{~min}$. in GSR conditioning studies. Perhaps, with longer intervals, the acquisition function would show an acceleration with successive trials rather than the usual decreasing function.

An initial step in this direction is reported by Schaub (1965). In his study, rate of adaptation appeared to be an inverse function of interstimulus interval. Furthermore, when long interstimulus intervals ( $3 \mathrm{~min}$.) were used, the GSR tended to increase over the first 10 trials. It would seem that this phenomenon is similar to the effect of maintaining Ss in the experimental situation since in both cases the magnitude of the GSR increased over time.

\section{References}

BINDRA, D., \& CAMERON, L. Changes in experimentally produced anxiety with the passage of time. J. exp. Psychol., 1953, 45, 197-203.

DIVEN, K. E. Certain determinants in the conditioning of anxiety reactions. J. Psychol., 1937, 3, 291-308.

GOLIN, S. Incubation effect: Role of awareness in an immediate versus delayed test of conditioned emotionality. J. abnorm. soc. Psychol., 1961, 63, 534-539.

LOVIBOND, S. H. Personality and conditioning. In B. Maher (Ed.), Progress in experimental personality research. Vol. 1. New York: Academic Press, 1964.

MEDNICK, M. T. Mediated generalization and the incubation effect as a function of manifest anxiety. J. abnorm. soc. Psychol., 1957, $55,315-321$.

SCHAUB, R. E. The effect of interstimulus interval on GSR adaptation. Psychon. Sci., 1965, 2, 361-362.

STEWART, M. A., STERN, J. A., WINOKUR, G。, \& FREDMAN, S. An analysis of GSR conditioning. Psychol. Rev., 1961, 68, 60-67. Note

1. This research was supported in part by a grant from the Research Development Fund of Dalhousie University. 